AperTO - Archivio Istituzionale Open Access dell'Università di Torino

\title{
Voting chances instead of voting weights
}

\section{This is the author's manuscript}

Original Citation:

Availability:

This version is available http://hdl.handle.net/2318/1659105

since 2018-01-24T17:44:34Z

Published version:

DOI:10.1016/j.mathsocsci.2012.12.003

Terms of use:

Open Access

Anyone can freely access the full text of works made available as "Open Access". Works made available under a Creative Commons license can be used according to the terms and conditions of said license. Use of all other works requires consent of the right holder (author or publisher) if not exempted from copyright protection by the applicable law. 
Review article

\title{
Voting chances instead of voting weights
}

\author{
Paolo Di Giannatale, Francesco Passarelli* \\ Bocconi University, Milan, Italy \\ University of Teramo, Italy
}

\section{A R T I C L E I N F O}

\section{Article history:}

Received 16 October 2012

Received in revised form

3 December 2012

Accepted 4 December 2012

Available online 21 December 2012

\begin{abstract}
A B S T R A C T
We study political distortions that emerge in situations where agents' political power is disproportionate with respect to their economic power. We use the Shapley value to evaluate both the economic and the political power. We show that usual weighted majority voting cannot prevent political distortions from emerging in a huge mass of situations. Distortions are less severe if partners can leave the union at low cost.

We propose an alternative voting method based on random assignments of voting rights. Agents are given chances to vote instead of weights. If chances are computed according to a specific formula, no political distortion occurs. As an application, we analyze the rotation voting system recently adopted by the European Central Bank. We find that this system yields an enormous amount of political distortion. Then we compute the voting chances that should be assigned to Eurozone countries in order to eliminate it.
\end{abstract}

(c) 2012 Elsevier B.V. All rights reserved.

\section{Contents}

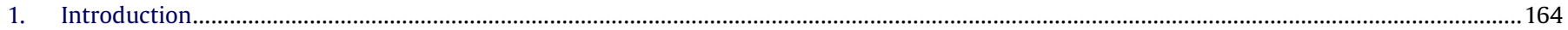

2. Preliminaries and related literature

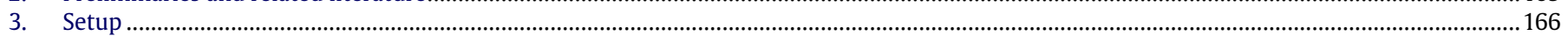

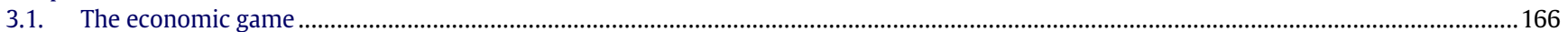

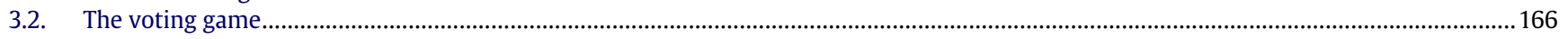

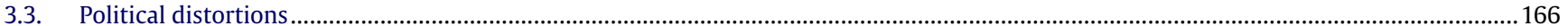

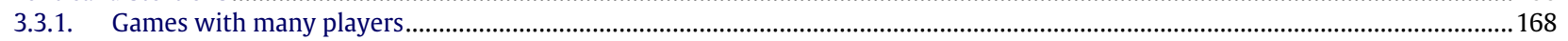

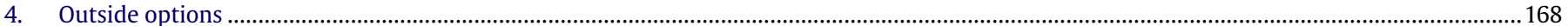

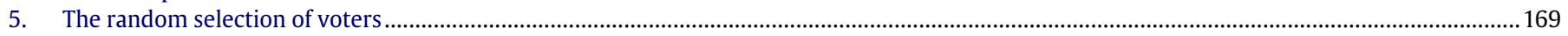

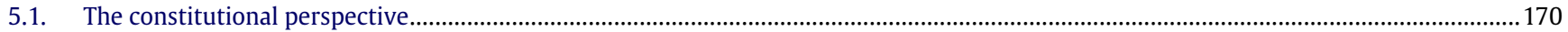

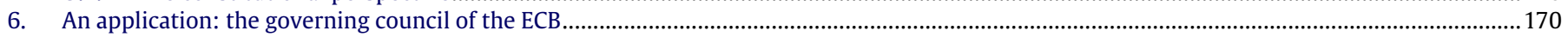

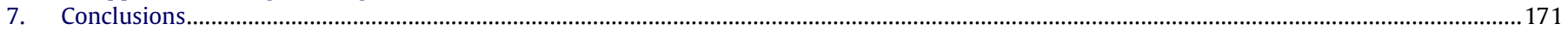

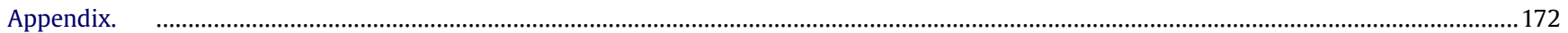

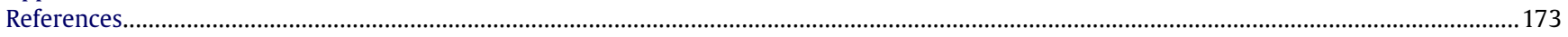

\section{Introduction}

Voting is probably the most common way to make collective decisions and tensions amongst partners are normal when there are differences of opinion about what to do. Nonetheless one would expect lower tensions when voting rules are fair. A common idea is that voting rules, such as majority threshold and vote weighting, can be chosen in order to guarantee enough representation for

\footnotetext{
* Corresponding author at: Bocconi University, Milan, Italy. Tel.: +39025836 5425; fax: +39 0258365439 .

E-mail addresses: paolo.digiannatale@unibocconi.it (P. Di Giannatale), francesco.passarelli@unibocconi.it (F. Passarelli).
}

the majority and sufficient protection for the minority. But how can we really judge the fairness of a voting system? Can weighted votes and super-majorities guarantee fairness?

These are old questions that we approach in the following perspective. Any common project among partners produces a certain amount of payoffs. Partners can be States in a federal context, factions in legislatures or boards, ethnic groups, companies in a joint venture, and so on. By common project we mean any kind of cooperation that yields a positive value, such as building a public infrastructure, implementing a common policy, launching a new product, etc. The value has to be split among partners. We consider two alternatives. First, the partners reach an agreement on payoff division through a negotiation process that we call "economic bargaining", in which bargaining power only derives from 
the way partners contribute to the payoff production. Second, the partners split the payoffs through a decision made by voting, in which power is given by voting rules, that define the way the partners contribute to the decision. We name the second alternative "political bargaining". We model the economic and the political bargaining as two games in coalitional form. Then we apply the same solution concept, the Shapley value, to these two games and compare the solutions. If they are different, then a certain amount of "political distortion" in payoff division occurs. Thus there might be situations in which a player gets a lot, not because he contributes a lot, but just because he has got a lot of voting rights.

One may conclude that too much distortion means unfair voting rules. But we do not take the avenue of analyzing how much distortion is tolerable in a fair voting system. We rather address three different questions, one positive and two normative. First, we want to see if, in the class of weighted voting games, it is always possible to set up a weight apportionment and a majority threshold that yield no distortion. The answer is "No". This class is too limited because weights are a discrete tool of power assignment. In other words, for a large mass of economic games, the solution cannot be replicated by a weighted voting game. Thus a certain amount of distortion, and possibly unfairness, is unavoidable.

Second, we study how political distortions are related to the players' chance of leaving the political group. We find that foreseeing a secession clause or a breakdown scenario among the constitutional or statutory provisions may reduce political distortions substantially. Notice that distortions do not decrease when secession occurs, but when secession becomes a viable alternative, a credible threat. This possibly explains why the European Union has introduced a secession clause in the recently adopted Lisbon Treaty.

Finally, we look for an alternative voting method that yields zero distortion. Instead of a certain amount of votes, a partner is given a chance of being selected for a one-vote right. For example, partner $a$ is not assigned, say, 3 votes, but rather he has, say, $47 \%$ probability of being selected for voting; partner $b$ has, say, $29 \%$ probability of being selected, instead of 2 votes.... Chances are a continuous tool of power assignment. Thus, for any economic game, it is always possible to find a distribution of selection probabilities such that expected political distortion is zero. We show how to compute these probabilities.

The random assignment of vote rights proposed here is not the unique mechanism that eliminates political distortions. However, we think that it is not so distant from what in reality happens in some international institutions like the IMF or the UN Security Council. Most countries do not have a permanent right to vote. Some of them are appointed as non-permanent members. Similarly, the European Central Bank has recently decided to adopt a new voting system in which governors of different countries are assigned the right to vote according to a rotation mechanism. The rotation speed depends on each country's economic relevance. In the last part of the paper, as an application, we measure the amount of distortion that this new system would produce. The picture is not encouraging: distortions are quite large, despite the reform. Then we show how an alternative distortion-free system based on random selection should be crafted.

We suggest that random selection is better than rotation or appointment, and possibly not too difficult to implement in practice. It should be adopted not only in supranational bodies, but in a wider range of situations, such as federal systems or boards.

The paper is organized as follows. Section 2 provides some basics on the Shapley-Shubik (SS) index and surveys the related literature. Section 3 illustrates the basic approach and analyzes the sources of political distortion. Section 4 explores the role of outside options in the political bargaining. In Section 5 we present the voting rule based on random selection and show how it can be applied to specific contexts or how to use it for drafting a constitution. Section 6 applies our findings to the Council of governors of the ECB while Section 7 concludes. All proofs are in Appendix.

\section{Preliminaries and related literature}

Our exercise amounts to analyzing the distortion that occurs when bargaining in a general negotiation context, such as the market, is replaced by bargaining in a voting context, such as a legislature. As pointed out earlier, since we want to focus only on the difference between economic and political games, not on the differences in the way we solve them, we use a common solution concept. We use the Shapley value to solve both bargaining games (Shapley, 1953). This solution is fully axiomatic and does not require any specific or contingent description of how negotiations take place. Moreover, it is based on a parsimonious set of axioms that can be given a normative reading in terms of fairness. ${ }^{1}$

Nonetheless, how the sub-coalitions form, whether they are stable, etc. are essential ingredients of the underlying bargaining games. We will come back to this point in Section 4. We will see that the way the political and the economic game interact is crucially determined by the availability of outside options and, ultimately, by the cost of leaving the political group.

The Shapley solution of a voting game is the Shapley-Shubik (SS) power index (Shapley and Shubik, 1954). ${ }^{2}$ L. Shapley and M. Shubik claim that their power measure is "ineluctable" since "any scheme for imputing power among the members of a committee system either yields the power index defined above or leads to a logical inconsistency" (Shapley and Shubik, 1954, p. 789).

Still a question remains: is political power a measure of a player's expected worth? Roth (1988a) shows how the Shapley value can be interpreted as an expected utility function and Laruelle and Valenciano (2003) provide an axiomatic foundation of this view. Moreover, Felsenthal and Machover (1998) point out that the SS index, being derived from a solution of a cooperative game, corresponds to a notion of "voting power as expected share in fixed total prize" (p. xiii). Roth (1988b) suggests the possibility that voting power and bargaining solution may be different, but only "when we are interpreting a simple game as something other than a transferable utility characteristic function game" (p. 8). Thus, the answer to the question above is "Yes" at least when there is a means to transfer utility, like side-payments. In this case the value of one player's votes is his SS index. This implies that a risk-neutral voter is indifferent between voting, with the prospect of getting his SS value, and by-passing voting if he is offered SS. In accordance with this literature, we claim that a player's SS index is not only a measure of his voting power, but also of the monetary value that he expects from playing a voting game. ${ }^{3}$ Nevertheless, a proportional agents' representation in voting does not ensure a proportional power: rather, this latter requires a non-proportional distribution of voting weights, as justified by Laslier (2012).

\footnotetext{
1 Myerson (1980) shows that Shapley's allocation rule guarantees fairness in political payoffs division, while Van den Brink (2002) demonstrates that any solution which satisfies symmetry and additivity, and this is the case, also satisfies fairness

2 Recent applications of power indices to decision-making in the European Union have stimulated a broad literature (an incomplete list includes Baldwin and Widgrén, 2004; Felsenthal and Machover, 2004; Napel and Widgrén, 2006, 2011; Braham and Holler, 2005; Laruelle and Valenciano, 2008b; Passarelli and Barr, 2007; Barr and Passarelli, 2009; Benati and Vittucci Marzetti, 2011) and a lively debate with some sceptical views (Garrett and Tsebelis, 1999).

3 Although the Shapley value is framed in the cooperative approach to the bargaining problem, there are in the literature several examples of non-cooperative (extensive form) games that yield the Shapley value. See for instance Gul (1989), Hart and Mas-Colell (1996), and Maskin (2003). These games represent credible descriptions of what happens in a purely economic environment (e.g. a market) as well as in a political environment (e.g. a legislature).

Recently, Laruelle and Valenciano (2007, 2008a, 2009) explore both the noncooperative foundations and the axiomatic properties of the SS as a measure of bargaining power
} 
Our main normative point in this paper is that political distortions can be reduced or avoided either by allowing for secession or by using probabilities of being selected for vote. As regards the role of a secession clause, to the best of our knowledge, no work has been done so far. As for the use of probabilities, Berg and Holler (1986) propose to randomize the qualified majority threshold as a means to avoid discrepancy between the seat distribution in a committee and an exogenous distribution of voting power. This idea is also present in Turnovec (2009). Unlike both of these works, we specifically analyze differences between economic and political power, and we study how the randomization mechanism should be computed based on the economic game played by the agents. Moreover, we explore the level of centralization of the political union by considering outside options in the political game.

Our work is related to another relevant body of literature which has investigated qualified majority and voting apportionments from a normative viewpoint. Laruelle and Valenciano (2004) characterize axiomatically the fairness properties of power indices. Choosing a power index entails choosing a measure of inequality. Fairness is also the main concern of Leech (2002), who proposes an algorithm to compute the weights and the majority threshold that equalize per-capita voting power of each member state in the EU Council. Casella (2005) suggests that the possibility of "storing" votes improves allocation when players have heterogeneous policy preferences. Casella et al. (2010) test this hypothesis. Alesina and Passarelli (2010) suggest that rules are optimal if they assign the pivotal role to the voter whose interests are similar to the social planner's ones. Instead, other authors prefer to use different measures of power. Aleskerov (2008), for instance, uses new power indices to examine the power distribution in the Russian parliament, while in Breton et al. (2012) the concept of nucleolus is applied to the EU Council of Ministers. These works are mainly concerned with efficiency issues, and they stick to "traditional" voting methods, such as weighted voting and super-majority rules.

In the present paper we focus on distributional problems, and our proposal of a randomization scheme somehow breaks with this tradition. The random selection of voters has recently become a popular topic of the law literature. The main concern is representation and fairness in general elections. Lpez-Guerra (2011) claims that if voters are randomly selected to cast their ballots, and they get well informed about the candidates, the quality of electoral outcomes improves with respect to universal suffrage. Other authors propose lottery voting, a system in which the winner representative is randomly drawn from a distribution that reflects how citizens have cast their votes (Amar, 1984). This system would guarantee better representation of the minorities and more turnout (Sewell et al., 2009). We share with this literature the basic idea that randomizing vote rights can improve fairness. We differ from it in the way random assignments of vote rights are derived. We do not look at the way citizens cast their votes but, more fundamentally, at the way citizens' interests are reflected by the payoff division in the economic game. Finally, our approach is perhaps more general and applies also to non-political committees.

\section{Setup}

\subsection{The economic game}

Consider a set $N=\{1, \ldots, n\}$ of players and denote with $2^{N}$ the set of all possible subsets (coalitions) of $N$. Let $\gamma: 2^{N} \longrightarrow[0,1]$ be the characteristic function which assigns a worth $\gamma(S)$ to any coalition $S \subseteq N$. One may interpret $\gamma(S)$ as the maximum payoff achievable by using the resources of the players in any coalition $S$.
Let $(N, \gamma)$ be a transferable-utility (TU) convex game, and call it the economic game. ${ }^{4}$ The economic game is solved by using the Shapley solution $\varphi(\gamma)=\left\{\varphi_{1}(\gamma), \ldots, \varphi_{n}(\gamma)\right\}$, where

$\varphi_{i}(\gamma) \equiv \sum_{S \subseteq N \backslash i} p(S) \cdot \Delta_{i} \gamma(S)$

with $p(S)=\frac{s !(n-s-1) !}{n !}, \Delta_{i} \gamma(S)=\gamma(S \cup i)-\gamma(S), s=|S|$, and $i=$ $1, \ldots, n$. Observe that $\Delta_{i} \gamma(S)$ is player $i$ 's marginal contribution to coalition $S$ and $p(S)$ can be considered as the probability of $S$, with the underlying idea that all players' orderings are equally likely (symmetry). Thus any player expects to be rewarded with her expected marginal contribution to the random coalition $S$. Observe also that $\sum_{i \in N} \varphi_{i}(\gamma)=\gamma(N)$ (efficiency). For the sake of simplicity and without loss of generality, we assume that $\gamma(N)=1$.

The interpretation is that, had the payers to bargain into the market for the division of the unit-payoff of an economic project, a likely and fair division would assign each player $i$ a share $\varphi_{i}(\gamma)$. Below we sometimes call $\varphi_{i}(\gamma)$ the economic solution in order to contrast it with the political solution described in the following section.

\subsection{The voting game}

Consider the same set $N$ of players. Let $(N, v)$ be a TU game and call it a voting game, where $v: 2^{N} \longrightarrow\{0,1\}$ is a simple characteristic function describing a voting situation as follows:

$v(S)= \begin{cases}1 & \text { if } S \text { is winning } \\ 0 & \text { if } S \text { is losing. }\end{cases}$

Solving the voting game with the Shapley value in (1) yields the Shapley-Shubik power index, SS:

$\phi_{i}(v) \equiv \sum_{S \subseteq N \backslash i} p(S) \cdot \Delta_{i} v(S)$

where $p(S)$ is the same as in (1). Let us interpret $v(S)$ as a usual characteristic function of a TU game: $v(S)$ represents the payoff, normalized to one, that originates from the political decision made by the members of coalition S. Reaching a majority is the only way to make this decision; and the decision is the only way to produce the payoff. What is relevant in the political game is forming a majority. The pivot is the voter who swings a coalition from losing to winning. His vote's worth is the full amount of the payoff. Any voter is rewarded by his chance to play a pivotal role. In fact, $\phi_{i}(v)$ in (2) represents voter $i$ 's probability to end up in a pivotal situation. Since utility is transferable, $\phi_{i}(v)$ may be assigned through monetary side-payments.

Voting games are weighted when voters are assigned a different amount of votes. Sometimes a qualified majority is required. If it is the case, the voting game is usually represented with $v=$ $\left(q ; w_{1}, \ldots, w_{n}\right)$, where $q$ denotes the majority threshold and $w_{i}$ is player $i$ 's number of votes (i.e. weight).

\subsection{Political distortions}

Assume that players cannot play the economic game without having formed a majority in the voting game. This reflects many real situations in which partners (States, provinces, regions, political factions, groups in corporations, ...) engage in a common

\footnotetext{
4 A game is convex if its characteristic function $\gamma$ is supermodular: $\gamma(S \cup T)+$ $\gamma(S \cap T) \geq \gamma(S)+\gamma(T), \forall S, T \subseteq N$, or equivalently: $\gamma(S \cup\{i\})-\gamma(S) \leq$ $\gamma(T \cup\{i\})-\gamma(T), \forall S \subseteq T \subseteq N \backslash\{i\}, \forall i \in N$. Supermodularity trivially implies superadditivity, therefore a convex game is superadditive too.
} 
project after having voted in committees or legislatures. Realistically, the decision in the voting game also specifies how the payoffs of an economic project will be distributed; i.e. the bill to be voted sounds like: "Let $\gamma(N)$ be produced and let it be distributed as specified in the present bill". In this case, the distributional provisions of the bill become the object of a "political bargaining" amongst voters, and side-payments which allow payoffs to be apportioned among players are possibly also included into the bill. In a way, political bargaining "replaces" economic bargaining, and political power substitutes economic power. ${ }^{5}$ Therefore voting rules rather than economic roles determine how payoffs are distributed. For example, a player that is rather unimportant in the economic game can get a lot if he is quite powerful in the political game. This causes what we call here a political distortion, i.e. a discrepancy between political and economic power which affects the payoff allocation. We measure the political distortion with the difference between the Shapley value of the political game (i.e. the SS index) and the Shapley value of the economic game.

Definition 1. Call PD (Political Distortion) the difference between the Shapley-Shubik index of the political game and the Shapley value of the economic game:

$P D(v, \gamma)=\phi(v)-\varphi(\gamma)$.

For player $i$,

$P D_{i}(v, \gamma)=\phi_{i}(v)-\varphi_{i}(\gamma)=\sum_{S \subseteq N \backslash i} p(S) \cdot\left[\Delta_{i} v(S)-\Delta_{i} \gamma(S)\right]$.

$P D_{i}$ represents the additional gain (the loss, if negative) that player $i$ enjoys when the payoff allocation is made within a political context instead of an economic contest, like the market. This gain can be very large if player $i$ has much more political power than economic power. Since both $\phi_{i}(v)$ and $\varphi_{i}(\gamma)$ sum up to one, then $\sum_{N} P D_{i}(\gamma, v)=0$. This means that the $P D_{i}$ 's represent pure redistributions amongst players, to the exclusive advantage of the players which are more politically than economically powerful. Let us see this point with an example.

Example 1. Consider an economic game $\left(N, \gamma^{1}\right)$ which consists of an agreement on the realization of a common infrastructure (an airport, a power plant, an oil pipeline, ...) amongst the three States of a federal country $(a, b, c)$. Suppose that their economies have different sizes and characteristics so that their contributions to the creation of a common value are different. Let the characteristic function of this economic game be the following: $\gamma^{1}(\emptyset)=0, \gamma^{1}(a)=0.3, \gamma^{1}(b)=0.1, \gamma^{1}(c)=0.2, \gamma^{1}(a, b)=$ $0.5, \gamma^{1}(a, c)=0.6, \gamma^{1}(b, c)=0.4, \gamma^{1}(a, b, c)=1$. For example, State $a$ is big and could build a rather large infrastructure that is worth $\gamma^{1}(a)=0.3$. Of course, it would make a larger one, which is worth 0.5 , if also State $b$ participates, $\gamma^{1}(a, b)=0.5$.

The Shapley value for this game is: $\varphi\left(\gamma^{1}\right)=\{0.43,0.23,0.33\}$ and reflects the players' expected contributions to the common value. For example, State $a$, the largest contributor, gets the largest share. Reasonably, this solution would be achieved if the three countries could negotiate in a market context.

\footnotetext{
5 Although distributional provisions, such as taxation or subsidies, are frequent in legislation, the assumption that the law includes those provisions is redundant in our analysis. In TU games the presence of a medium of payment allows the players to share $\gamma(N)$ even without specific law provisions. What allows the legislative bargaining to replace the economic one is specifically the fact that $\gamma(N)$ cannot be produced without the political decision. Note that $v(N)$ does not imply that all players are in the majority. It rather means that the majority decision has been reached, and that decision is enforced to the minority too.
}

Suppose that the agreement can be implemented only if there is a formal decision made by simple majority, in which every country has one vote. In this case, the political game is $v^{1}=(2 ; 1,1,1)$. The SS solution is $\phi\left(v^{1}\right)=\{0.33,0.33,0.33\}$. Since all countries count the same in the political game, they expect to be rewarded the same for casting their vote. Therefore, the vector of political distortions is $P D\left(v^{1}, \gamma^{1}\right)=\{-0.1,+0.1,0\}$. Thus player $a$ suffers a loss from having less political power than economic power. On the contrary, the economically weak country $b$ takes advantage from being equally important as the other players in the political decision. In some sense, $P D_{a}\left(v^{1}, \gamma^{1}\right)=-0.1$ represents a transfer made by $a$ to $b$ for having $b$ taking part in the joint political decision.

Example 1 illustrates that political distortions may be large when voting weights do not reflect economic power. As pointed out earlier, an important assumption so far is that a common political decision is the only way to realize the common project. The partners by no means can undertake even a small part of the project without the permission of the majority. In our example, this entails a high level of centralization, which is in fact what happens realistically when some policy areas are the exclusive competence of the central government (energy policy, infrastructures/environment, monetary policy, defense, foreign policy, ... $){ }^{6}$ Thanks to this assumption, the political game can be described with a simple characteristic function. Players have no outside option and the solution is the Shapley-Shubik index. In case the partners have the option to quit the group and undertake the project on their own, the political game is no longer simple. We come back to this point in Section 4, where we show that things may change substantially.

We wonder now if there is any chance to eliminate political distortions by using appropriate weights and majority thresholds. The question is: given an economic game, is it always possible to find a weighted voting game with the same solution? In this case, the $P D_{i}$ 's would be zero for all players. The answer to this question is "No". There is a class of economic games, which we show is a huge one, whose solutions cannot be replicated by the solution of any (possibly weighted) voting game. For economic games in this class, a certain amount of political distortion is unavoidable. Take game $\left(N, \gamma^{1}\right)$ of Example 1. a's weight is possibly too low. However, it is impossible to find a weight apportionment and a majority threshold such that $\phi_{a}=0.43$. The reason is that with three players the class of SS solutions of all possible weighted voting games is relatively small and it does not include 0.43 , whereas the class of economic games' solutions is an infinite set, dense in $[0,1]$ (see Fig. 1 below).

Proposition 1. Let $\Gamma$ be the set of all TU economic games $(N, \gamma)$ and let $\Sigma$ be the set of all voting games. For any $i \in N$, (i) the set of all Shapley values $\left\{\varphi_{i}(\gamma):(N, \gamma) \in \Gamma\right\}$ is a dense subset of $[0,1]$; (ii) the set of SS values $\left\{\phi_{i}(v):(N, v) \in \Sigma\right\}$ is a non-dense subset of $[0,1]$.

The idea from Proposition 1 is that voting games are unable to yield all allocations that for example a market may guarantee. The class of political solutions is too little: the economic value of a player can be any point in $[0,1]$, whereas the space of all political solutions (i.e. the set of all SS indices for that player) is only a discrete collection of points in the unit interval. In other words, the set of political solutions has "holes" in that interval. If the economic solution is in one of those holes, there is political distortion. Thus a player's value of playing an economic game is different from his value of playing a political game.

\footnotetext{
6 This is also what happens in non-political contexts, such as companies, organizations, condominiums, ....
} 


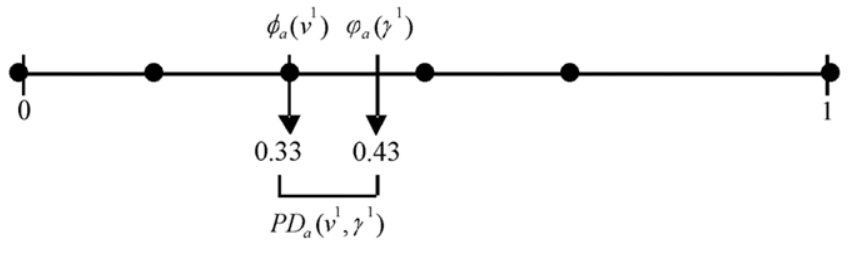

Fig. 1. Political distortions with three players.

This is the case of player $a$ (and $b$ ) in game $\gamma^{1}$ of Example 1 . Fig. 1 offers a graphical representation of the distortion suffered by player $a$ (which amounts to $P D_{a}\left(v^{1}, \gamma^{1}\right)=-0.1$ ) if the political game $v^{1}$ is adopted. The bullet points represent the political solutions of other possible voting games. With three players the set of all SS solutions consists of six bullet points "only": $\Psi_{i}(\Sigma)=\left\{0, \frac{1}{6}, \frac{1}{3}, \frac{1}{2}, \frac{2}{3}, 1\right\} .{ }^{7}$ For example, a voting game like $v^{2}=$ $(5 ; 3,1,2)$ with more "proportionate" weights would grant player $a$ with $\phi_{a}\left(v^{2}\right)=1 / 2$. However, still a certain amount of political distortion occurs also in this case.

An economic solution can be any point in the unit interval, whereas a political solution belongs only to a limited set of points. This means that political distortions are quite likely in reality. Choosing weights that better reflect economic power may reduce distortions in many cases, but they might not eliminate distortions completely. As we have seen, with $v^{2}$ the political distortion suffered by $a$ is lower but it is still positive.

\subsubsection{Games with many players}

One would expect that the gap between an economic solution and the closest political solution is decreasing in the number of players. This is in fact what happens. In the limit, the set of political solutions is the interval $[0,1]$, then it coincides with the set of economic solutions.

Proposition 2. As $n \rightarrow \infty, \Psi_{i}(\Sigma) \rightarrow \Psi_{i}(\Gamma)$.

This means that, when the number of players is infinite, for any economic game $\gamma \in \Gamma$ it is possible to find a weighted voting game $v(\gamma) \in \Sigma$ such that each player receives the same payoffs from the two games. Put differently, with a larger number of players there are more chances of finding a weight apportionment with small political distortion. The reason is that as the number of players increases the set of political solutions (the set of bullet points) becomes less and less coarse. This leads to the conclusion that political distortion induced by weighted voting is a relevant problem in situations with a fairly small number of players. Vice versa, if correctly chosen, weighted votes are effective when applied to large committees or boards. Somehow paradoxically, in reality we observe the opposite: a limited use of weights in situations where the number of voters involved is quite large.

\section{Outside options}

So far we have assumed that partners have no outside options in the political game. Minority groups cannot undertake smaller projects by their own initiative nor they can disobey the will of the majority and step out of the project. The decision about the project can be taken only through a centralized political process. This

\footnotetext{
7 Let us see why the set of all SS solutions with three players consists of these six points. Recall that $p(S)$ in $(2)$ is $\frac{s !(n-s-1) !}{n !}$. Observe that, with three players, $p(S)$ can only have two values: $\frac{1}{3}$ and $\frac{1}{6}$. Political payoffs can only be given by weighted sums of these two values, where weights can only be integers from 0 to 2 . It is easy to verify that there is no allocation of votes such that $\phi_{i}(\cdot)=\frac{5}{6}$. Thus $\Psi_{i}(\Sigma)=\left\{0, \frac{1}{6}, \frac{1}{3}, \frac{1}{2}, \frac{2}{3}, 1\right\}$.
}

legitimizes the use of simple characteristic functions for describing weighted voting: majority coalitions yield the full payoff and minority coalitions get zero. No coalition, apart from a winning one, can produce any payoff.

The underlying notion of political union is rather rigid. It corresponds to a high level of centralization in which given decisional areas are the exclusive competence of the political institution (States, federal systems, boards in companies, ... ). This is compatible with the traditional concept of a sovereign state, in which the state itself is indivisible and it does not give up any of its components (e.g. territories, competencies, etc.). This usually applies also to confederate and federal unions which do not allow for secession rights, although there are a few examples in which such rights are recognized, at least formally (e.g. Canada or the former Yugoslavia).

What would one expect with a lower level of centralization, such that partners can subtract themselves from the majority's will? Is political distortion still there? We find that if centralization decreases, also the political distortion decreases and it can even disappear in a totally decentralized political scenario. The reason is that partners have outside options. They can undertake projects on their own and get a positive payoff.

Suppose that partners have the option of realizing the project unilaterally (or together with sub-groups of agents). In this event, however, they bear a "political cost". We interpret this cost as consisting in a fine that they must pay to the members that remain with the union. Let us assume that this payment is proportional to the payoff of the unilateral project. For example, if doing the project by myself yields 0.3 , I have to pay $(1-\alpha) \cdot 0.3$ of political cost and I get $\alpha \cdot 0.3$ as net payoff. ${ }^{8}$ We claim that if $\alpha$ lowers down to zero, the political distortion decreases until it disappears. Let us see this with our three-State example.

Example 2. Take the economic game $\left(N, \gamma^{1}\right)$ and assume that the States have the option to leave the union and pay a "fine" which is a share $(1-\alpha)$ of their payoffs. Call $\left(N, v^{2}\right)$ the "new" political game. The characteristic function is the following.

$-v^{2}(\emptyset)=0$.

- Single players get economic payoffs minus the fine: $v^{2}(a)=$ $\alpha \gamma^{1}(a)=\alpha \cdot 0.3 ; v^{2}(b)=\alpha \cdot 0.1 ; v^{2}(c)=\alpha \cdot 0.2$.

- Two-State coalitions get the economic payoff plus the fine paid by the player who has left the union: $v^{2}(a, b)=\gamma^{1}(a b)+(1-$ $\alpha) \gamma^{1}(c)=0.5+(1-\alpha) \cdot 0.2 ; v^{2}(a, c)=0.6+(1-\alpha)$. $0.1 ; v^{2}(b, c)=0.4+(1-\alpha) \cdot 0.3$.

- Finally, $v^{2}(a, b, c)=1$.

The Shapley solution for this political game is:

$$
\begin{aligned}
& \phi_{a}\left(v^{2}\right)=0.33+\alpha \cdot 0.1 \\
& \phi_{b}\left(v^{2}\right)=0.33-\alpha \cdot 0.1 \\
& \phi_{c}\left(v^{2}\right)=0.33
\end{aligned}
$$

Interestingly, as soon as the fine for leaving the union approaches zero (i.e. $\alpha \rightarrow 1$ ), the political payoffs converge to the economic payoffs: the political distortion disappears (i.e. $\phi\left(v^{2}\right) \rightarrow \varphi\left(\gamma^{1}\right)$ ).

The intuition is clear. If leaving the union is cheap, the partners in the minority are simply better off not participating. Outside options cannot be ignored in the political bargaining. As a result, the political game subsumes the underlying economic bargaining game.

\footnotetext{
8 In a sense, $\alpha$ parameterizes the level of centralization of the political group. If $\alpha=0$, there is no centralization: players bear no cost if they leave the group; their outside option is fully available. If $\alpha=1$, there is perfect centralization: players cannot abandon the political union and get a positive payoff.
} 
Proposition 3. As $\alpha \rightarrow 1, P D_{i}(v, \gamma) \rightarrow 0$ for all $i$. The political distortion is positively related to the cost of leaving the political union.

This model predicts that political distortions due to majority voting are an issue whenever breaking (by leaving the group or not adhering to the majority will) is a costly option. Interestingly, when the cost is zero, players' threats of doing things by their own affect the political bargaining in the same way as they would affect the economic bargaining.

If any player has an incentive to pay the fine and do the project by himself, the others leave him at least with his net stand-alone payoffs. The outcome is that nobody leaves the union, the project is realized and no Pareto inefficiency occurs. Therefore, allowing for a "secession clause" into a constitution mitigates the effects of voting rights malapportionments and lowers the potential for internal distributive conflicts. This possibly explains why the possibility of leaving the European Union by any member country has been explicitly introduced in the recently adopted Lisbon Treaty.

We have modeled the cost of not adhering to the majority's decision as a purely redistributive mechanism based on fines. No inefficiency occurs. This is consistent, for example, with the rules of the Stability Pact of the European Monetary Union. ${ }^{9}$ One might alternatively think that sticking with the union is a "money burning" mechanism, like in the case of a secession war. The union generates collective losses which may imperil the project and lead to the breakup of the union itself. ${ }^{10}$ Exploring this kind of inefficiency is beyond the scope of this paper. We leave it for future extensions.

\section{The random selection of voters}

So far we have followed a positive approach. We have shown that, given an economic game, unless the number of players is infinitely large, it may be impossible to find a voting rule based on qualified majority and weighted votes which reduces political distortions to zero. We have also shown that allowing for a secession clause mitigates the effect of political distortions. Hereafter we take a normative perspective, in which we suggest a different voting method that, for any economic game, eliminates political distortion. With this method agents are randomly selected, with given probabilities, to take part in a group that will make the political decision by a simple majority.

Political distortions have been defined above as the difference between the expected value of playing the political game (i.e. the Shapley-Shubik index) and the expected value of playing the economic one (the Shapley value). The problem is that when the political game is a weighted majority voting the two payoffs do not always coincide. Intuitively, this problem arises because weighted voting is a discrete method for generating political power. Our aim here is finding a continuous method; i.e. a voting method whose expected payoff can be any real number. The idea is giving "chances" to participate in voting rather than "weights". Let us illustrate this method by following up Example 1.

Example 3. We want a voting method, call it $v^{r}\left(\gamma^{1}\right)$, whose Shapley-Shubik index is $\phi\left(v^{r}\left(\gamma^{1}\right)\right)=\{0.43,0.23,0.33\}$. Let us describe $v^{r}$ as follows: "the way payoffs are shared will be decided with probability $10 \%$ by $a$ alone; with probability $20 \%$ by $a$

\footnotetext{
9 Any country which breaks the public deficit target has to refund the other members with a fine that is proportional to its GDP.

10 For instance, one may think that politically weak but economically strong partners feel entitled to higher payoffs. Their sense of aggrievement leads them to destroy the others' payoffs through a war. This is a Pareto suboptimal mechanism and the resulting political game does not satisfy superadditivity. The outcome is the breakdown of the union.
}

and $c$; with probability $70 \%$ by $a, b$, and $c$ in simple majority voting". It is easy to see that for this voting game $a$ 's expected payoff is $\phi_{a}\left(v^{r}\left(\gamma^{1}\right)\right)=10 \% \cdot 1+20 \% \cdot 1 / 2+70 \% \cdot 1 / 3=0.43$. Similarly, $\phi_{b}\left(v^{r}\left(\gamma^{1}\right)\right)=70 \% \cdot 1 / 3=0.23$, and $\phi_{c}\left(v^{r}\left(\gamma^{1}\right)\right)=0.33$. No political distortion occurs.

One possible description of the voters' random selection is that one ball is drawn from a box that contains $10 \%$ blue balls, $20 \%$ green balls and $70 \%$ red balls. Blue means that only $a$ will vote; green means that $a$ and $c$ will vote; red means that all players will vote. The idea in Example 3 is that rational risk-neutral agents are indifferent between being selected for voting, with the risk of getting low or high payoffs, and agreeing in advance on a division that reflects their expected SS values. For example, player $c$ is indifferent between getting 0.33 in advance and accepting the random selection with $10 \%$ chance of getting nothing, $20 \%$ chance of getting $1 / 2$ and $70 \%$ chance of getting $1 / 3$. All players split the available wealth in the same way as they would have split it into the market.

A key role in this voting method is played by the chance of being selected for the voting game. We will show that for any economic game it is possible to find a "chance allocation" such that political distortions are zero. Let us first describe how to compute these chances for a generic economic game. Then we define the Random Selection Voting Rule (RSVR). Finally we show that no political distortions occur if the RSVR is adopted.

Consider the economic game $(N, \gamma)$, and its Shapley solution $\varphi(\gamma)$. Re-label the players following the decreasing order of their Shapley values: player 1 is the one with the largest Shapley value (player $a$ in the example); player 2 is the next one ( $c$ in the example), and so on:

$\varphi_{1}(\gamma) \geq \varphi_{2}(\gamma) \geq \cdots \geq \varphi_{n}(\gamma)$.

Players are listed in terms of their economic relevance in $\gamma$, as measured by the Shapley value. Call $v^{m},(m=1, \ldots, n)$ the simple majority game that includes the first $m$ players in the Shapley value ranking (from 1 to $m$ ). We have $n$ simple majority voting games. Player 1 has the chance to vote in games $v^{1}, v^{2}, \ldots, v^{n}$; he always votes. Player 2 participates in one of games $v^{2}, v^{3}, \ldots, v^{n}$, but not in $v^{1} ; \ldots$ player $n$ has only the chance to participate in $v^{n}$ together with all the other players:

\begin{tabular}{|l|l|l|l|l|l|}
\hline & \multicolumn{5}{|c|}{ Simple majority games } \\
\hline Players & $v^{1}$ & $v^{2}$ & $\cdots$ & $v^{n-1}$ & $v^{n}$ \\
\hline 1 & $\bullet$ & $\bullet$ & $\cdots$ & $\bullet$ & $\bullet$ \\
\hline 2 & & $\bullet$ & $\vdots$ & $\bullet$ & $\bullet$ \\
\hline$\vdots$ & & & $\ddots$ & $\ldots$ & $\ldots$ \\
\hline$n-1$ & & & & $\bullet$ & $\bullet$ \\
\hline$n$ & & & & & $\bullet$ \\
\hline
\end{tabular}

The "chance allocation" amounts to generating a probability distribution over the set of the $v^{m}$ games $(m=1, \ldots, n)$.

Definition 2. An $R S V R$ for $(N, \gamma)$ is a probability distribution over the set of $v^{m}$ such that

$\operatorname{Pr}\left(v^{m}\right)= \begin{cases}m \cdot\left[\varphi_{m}(\gamma)-\varphi_{m+1}(\gamma)\right] & \text { for } m=1, \ldots, n-1 \\ m \cdot\left[\varphi_{m}(\gamma)\right] & \text { for } m=n .\end{cases}$

In words, an RSVR is a voting rule by which voters are randomly selected to participate in a committee that decides by a simple majority. A committee of $m$ members includes the $m$ most economically relevant players. The probability of forming that committee is computed according to (5). 
Our main point is the following.

Proposition 4. For any economic game $(N, \gamma)$, no political distortions occur if the political game is based on the RSVR defined above.

What is relevant here is not weighted votes but probabilities to participate in voting. Players with more economic power are assigned higher probability. If probabilities are computed correctly, then players expect from the voting game exactly what they would expect from the political game. This voting method replicates the outcome that would be produced by a market mechanism in which players' bargaining power only derives from their relevance in the economic game. ${ }^{11}$

Proposition 4 may be interpreted in a large number perspective, where the $x_{j}$ 's are frequencies rather than probabilities. Suppose the economic game $(N, \gamma)$ is repeated many times. At any time there will be a different subset of players selected to make the political decision. Reasonably, the selected players will split the payoff equally among themselves, leaving the others with zero. After a large number of times, the total SS payoffs of any player will approximate the total Shapley values of the economic games.

Notice that the RSVR proposed here is not the unique mechanism which eliminates political distortions. What makes it desirable and possibly easy to implement in real situations is simplicity and fairness. As pointed out earlier, random selection is not observed in reality. There are cases in which players accept to rotate in voting (e.g. ECB). In other cases, differently sized groups of players select one representative which may or may not have weighted votes (e.g. IMF or the UN Security Council). Both rotation speed and selection of representatives are discrete mechanisms which (partially) eliminate distortions only if the game is repeated a large number of times. With an RSVR expected distortions can be made arbitrarily small even for economic games which are played a limited number of times.

\subsection{The constitutional perspective}

So far we have implicitly assumed that the regulator which has the power to enforce the voting rule also has a precise knowledge of the economic game. In fact, in a typical "constitutional" perspective the regulator has the power to establish the rules or voting protocol but it has no concise knowledge of the worth attainable to each coalition. Moreover, the voting protocol cannot be changed any time partners play a different economic game. What can be said in this case? Suppose that the regulator has to write a single voting rule for a long-term partnership amongst different agents. Examples are treaties of supranational institutions, constitutions of federal unions, or even statutory provisions for merging companies or joint ventures. The regulator ignores all future economic games, but it may know the game that will be played "on average". If the RSVR is computed on this average game, distortions will be eliminated "on average".

Proposition 5. Let $\left\{\left(N, \gamma_{1}\right), \ldots,\left(N, \gamma_{t}\right)\right\}$ be a set of $t$ economic games played by the agents in $N$. Call $(N, \bar{\gamma})$ the average game of this set, where, for any $S \in 2^{N}, \bar{\gamma}(S)=\frac{1}{t} \sum_{j=1}^{t} \gamma_{j}(S)$. The average political distortion is zero if the payoffs of each game in the set are split using the RSVR based on the average game.

\footnotetext{
11 Observe that with the RSVR individuals are given a lottery "over simple majority games". Requiring that for all $i$ the solution of the RSVR equals $\varphi_{i}(\gamma)$ implies that any player is neutral to what Roth calls "ordinary risk" (Roth, 1988a, pp. 57-58). Laruelle and Valenciano (2003) provide further insights on the ordinary risk neutrality involved here. The reader may notice that the result in Proposition 4 derives from the idea that any payoff vector can be obtained as a linear combination of games whose solutions are equal divisions amongst participants.
}

This proposition amounts to saying that in the long run total political distortion is zero if the selection probabilities of the RSVR are set by looking at the average game $\bar{\gamma}(S)$.

Let us see more specifically how $\bar{\gamma}(S)$ and the selection probabilities should be computed in this constitutional perspective. The Social Planner ignores the different roles that players will have in future economic games. Let us assume it can identify, for any player $i$, some measure of his economic relevance, $P_{i}$. If no information is available about future economic projects it is natural to expect that each player's contribution is proportional to his economic relevance. Examples of economic relevance are population, GDP, capital endowments, natural resources, stock shares in the company, $\ldots$, or appropriate convex combinations of these measures. Order the players by their economic relevance (i.e. $i<j \Leftrightarrow P_{i}>P_{j},(i, j \in$ $N)$ ). Take $P_{i}$ as $i$ 's expected marginal contribution to any coalition and define the average economic game as follows:

$\Delta_{i} \bar{\gamma}(S) \equiv P_{i}$.

Corollary 6 below characterizes the selection probabilities in the RSVR.

Corollary 6. If the RSVR is such that

$$
\begin{aligned}
& \operatorname{Pr}\left(v^{m}\left(P_{1}, \ldots, P_{n}\right)\right) \\
& \quad= \begin{cases}m \cdot\left(P_{m}-P_{m+1}\right) & \text { for } m=1, \ldots, n-1 \\
m \cdot P_{m} & \text { for } m=n\end{cases}
\end{aligned}
$$

the expected political distortions are zero.

The idea is simple. In a constitutional perspective economic relevance captures how a player will contribute on average. No political distortion occurs on average if random selection is based on economic relevance as specified by (7).

\section{An application: the governing council of the ECB}

With a view to large-scale enlargements of the euro area, a new voting mechanism based on the rotation of governors was adopted in 2002 for the Governing Council of the European Central Bank. ${ }^{12}$ The new mechanism will be implemented as soon as the number of members in the euro area exceeds 18. At the present time this number is 17 and all governors have the right to vote. In this section we measure the political distortions generated by the new rotation mechanism. We show that the distortions are quite high. Then we compute the RSVR which would lower distortions to zero. ${ }^{13}$

Under the new mechanism, the number of governors exercising a voting right does not exceed 15 . Governors rotate in and out of the voting right after one month. Countries are split in three groups, based on the size of their economies. Rotation speed varies across groups. Assuming that all the $27 \mathrm{EU}$ members have adopted the single currency, the first group is made by the five biggest countries. Four governors out of five have vote rights. Thus, the permanence rate in the first group is $4 / 5$. The mid-sized countries are 14 , and their permanence rate is $8 / 14$. The remaining 8 small countries have a $3 / 8$ permanence rate. The six members of the Executive Board have a permanent vote right. Thus the total number of votes is 21 .

We build the rotation voting game, $v_{R}$, as follows. There are 15 voting governors with one vote each. A not totally unrealistic

\footnotetext{
12 The Governing Council is the main decision-making body of the European Central Bank. It consists of the six members of the Executive Board, plus the governors of the national central banks of the euro area countries.

13 Recently a power analysis of the new rotation system has been carried out by Belke and Von Schnurbein (2012). They provide measurements for both traditional SS indices and preference-based indices.
} 
Table 1

Political distortions in the ECB governing council.

\begin{tabular}{|c|c|c|c|c|c|c|c|}
\hline \multicolumn{5}{|l|}{ Rotation rule } & \multicolumn{3}{|c|}{ Random selection rule } \\
\hline Col. 1 & Col. 2 & Col. 3 & Col. 4 & Col. 5 & Col. 6 & Col. 7 & Col. 8 \\
\hline Country & $\begin{array}{l}\text { Perm. rate } \\
\text { frequencies }\end{array}$ & $\begin{array}{l}\text { Polit. power }{ }^{\mathrm{a}} \\
\phi_{i}\left(v_{R}\right)\end{array}$ & $\begin{array}{l}\text { Econ. power } \\
\varphi_{i}(\bar{\gamma})\end{array}$ & $\begin{array}{l}\text { Distortion } \\
P D_{i}\left(v_{R}, \bar{\gamma}\right)\end{array}$ & $\begin{array}{l}\text { Sel. chance } \\
\text { frequencies }\end{array}$ & $\Delta$ Sel. chance & $\begin{array}{l}\text { Distortion } \\
P D_{i}\left(v_{R S}, \bar{\gamma}\right)\end{array}$ \\
\hline Germany & $4 / 5$ & 5.33 & 20.40 & -15.07 & 100 & 4.45 & 0 \\
\hline France & $4 / 5$ & 5.33 & 15.95 & -10.62 & 95.55 & 3.86 & 0 \\
\hline UK & $4 / 5$ & 5.33 & 14.42 & -9.09 & 92.49 & 8.37 & 0 \\
\hline Italy & $4 / 5$ & 5.33 & 11.63 & -6.30 & 84.12 & 11.24 & 0 \\
\hline Spain & $4 / 5$ & 5.33 & 8.82 & -3.49 & 72.88 & 21.50 & 0 \\
\hline Netherlands & $8 / 14$ & 3.81 & 4.52 & -0.71 & 51.38 & 9.12 & 0 \\
\hline Poland & $8 / 14$ & 3.81 & 3.00 & 0.81 & 42.26 & 2.38 & 0 \\
\hline Sweden & $8 / 14$ & 3.81 & 2.66 & 1.15 & 39.88 & 0.80 & 0 \\
\hline Belgium & $8 / 14$ & 3.81 & 2.56 & 1.25 & 39.08 & 1.62 & 0 \\
\hline Austria & $8 / 14$ & 3.81 & 2.38 & 1.43 & 37.46 & 2.40 & 0 \\
\hline Greece & $8 / 14$ & 3.81 & 2.14 & 1.67 & 35.06 & 2.86 & 0 \\
\hline Denmark & $8 / 14$ & 3.81 & 1.88 & 1.93 & 32.20 & 5.04 & 0 \\
\hline Portugal & $8 / 14$ & 3.81 & 1.46 & 2.35 & 27.16 & 0.13 & 0 \\
\hline Finland & $8 / 14$ & 3.81 & 1.45 & 2.36 & 27.03 & 0.14 & 0 \\
\hline Ireland & $8 / 14$ & 3.81 & 1.44 & 2.37 & 26.89 & 4.65 & 0 \\
\hline Czech Rep. & $8 / 14$ & 3.81 & 1.13 & 2.68 & 22.24 & 0.16 & 0 \\
\hline Romania & $8 / 14$ & 3.81 & 1.12 & 2.69 & 22.08 & 3.40 & 0 \\
\hline Hungary & $8 / 14$ & 3.81 & 0.92 & 2.89 & 18.68 & 7.56 & 0 \\
\hline Slovakia & $8 / 14$ & 3.81 & 0.50 & 3.31 & 11.12 & 3.23 & 0 \\
\hline Bulgaria & $3 / 8$ & 2.50 & 0.33 & 2.17 & 7.89 & 0.40 & 0 \\
\hline Luxembourg & $3 / 8$ & 2.50 & 0.31 & 2.19 & 7.49 & 0.21 & 0 \\
\hline Slovenia & $3 / 8$ & 2.50 & 0.30 & 2.20 & 7.28 & 2.20 & 0 \\
\hline Lithuania & $3 / 8$ & 2.50 & 0.20 & 2.30 & 5.08 & 0.46 & 0 \\
\hline Cyprus & $3 / 8$ & 2.50 & 0.18 & 2.32 & 4.62 & 0.96 & 0 \\
\hline Latvia & $3 / 8$ & 2.50 & 0.14 & 2.36 & 3.66 & 0.75 & 0 \\
\hline Estonia & $3 / 8$ & 2.50 & 0.11 & 2.39 & 2.91 & 1.56 & 0 \\
\hline Malta & $3 / 8$ & 2.50 & 0.05 & 2.45 & 1.35 & 1.35 & 0 \\
\hline
\end{tabular}

${ }^{\mathrm{a}}$ Columns 3-8 are in percentages.

hypothesis is that governors vote in the interest of their home countries. ${ }^{14}$ We assume that the six permanent members of the Executive Board always vote together. Therefore there is a 16 th voter who has got 6 votes. The majority threshold is 11 votes. The SS indices in this 16 players game are $37.5 \%$ for the Executive Board and $4.2 \%$ for each voting governor. Since governors do not always vote, in order to compute their actual political power we multiply this value by the permanence rates, then we normalize the governors' power to one in order to have a better idea of how payoffs are split (see Table 1 column 3 ). ${ }^{15}$

Country ranking within the rotation system is based on a composite indicator built on two parameters: the country's GDP (weighted 5/6), and the country's share of the total IMF aggregated balance sheet. We use this indicator also as a measure $P_{i}$ of economic relevance. Then we build the expected economic game, $\bar{\gamma}$, using identities (6). With this framework, each country's Shapley value is given by its own measure of economic relevance, as listed in column 4 of Table 1.

Consistent political distortions are expected to occur with the rotation mechanism. Despite the six most economically relevant countries may cast their votes more frequently, their political power is systematically lower than their economic power. The rotation mechanism is not able to prevent the occurrence of a huge aggregate political distortion: total transfers from the first six

\footnotetext{
14 By contrast, if this was not the case, there would be no need of any rotation system.

15 For example, the power of any of the four largest countries is computed as follows:

$4.2 \% \cdot \frac{4}{5} \cdot \frac{1}{1-0.375}$

The idea behind normalization is that, differently from countries, the Executive Board does not enjoy any economic benefits from participating in voting.
}

members to the remaining 21 amount to $45.28 \%$ of total aggregate payoffs.

As we know a Random Selection Rule may solve this problem. Given the measures of economic relevance (col. 4), formula (7) allows for computing the countries' admission chances, in a random selection game that we call $v_{R S}$. These chances are listed in columns 6 and 7. They should be read as follows: "Germany has $4.45 \%$ probability of being the sole country voting; it has $3.86 \%$ chance of voting together with France only; it has $8.37 \%$ chance of being together with France and UK only, .... France has 3.86\% chance of voting with Germany only; $8.37 \%$ of being together with Germany and UK only...." An alternative way to read this system, that refers to col. 6, is: "Germany should vote $100 \%$ of times; France should vote $95.55 \%$ of times; UK should vote $92.49 \%$ of times...."

Ideally, the group of governors that vote in the Governing Council may actually be selected by drawing a ball from a box which contains a large number of balls. $4.45 \%$ of these balls are marked "Germany", meaning that if that kind of ball is drawn, only Germany will have voting right. $3.86 \%$ of the balls are marked "Germany and France". 8.37\% of balls are marked "Germany, France and UK"....

With this voting method no political distortion occurs: political payoffs equal economic payoffs.

\section{Conclusions}

Our contribution in this paper is twofold. First, on the positive side, we show that in a large mass of cases voting weights are not sufficient to balance economic with political power.

Second, on the normative side, we propose an alternative method based on random selection of voting rights. Partners are selected for voting according to a precise probability distribution, with the chance of voting in a small group and getting a lot, but also the risk of not voting at all and getting zero. Of course, more 
economically relevant partners must have a higher chance to be selected. The probability distribution may be set up such that political power equals economic power. We argue that a rational risk-neutral agent would be indifferent between playing this kind of voting game and accepting a sure payment which amounts to the monetary equivalent of his economic power.

This paper suggests that the ancestral "democratic" principle of granting all members a permanent right to vote may lead in the long run to an enormous amount of undesired wealth redistribution among partners. Methods with rotating members, like the ones adopted by the ECB or the UN Security Council, may reduce but not completely counteract political distortions.

This paper also suggests that the political distortion is crucially determined by the nature of the political pact. Distortions are lower when partners have the chance to break the pact (e.g. seceding, leaving a federation, withdrawing from a joint venture, ...). Eventually, this can be done at a cost. We find that when this cost is zero, no political distortion occurs and the political bargaining subsumes perfectly the underlying economic bargaining. In other words, including a secession clause or a breakdown scenario among the constitutional or statutory provisions reduces distortions substantially.

Finally some caveats. First, risk neutrality may not be the most appropriate way to look at preferences over political issues, and in many cases side-payments may not be feasible. Unfortunately removing quasi-linear preferences would imply a critical departure from this approach. Second, the use of partition functions instead of characteristic functions might improve the analysis of coalition formation in economic games with outside options. Third, in this paper we have considered only a quite simplified voting scheme: direct voting in committees or unicameral representative democracies, in which the representatives of the same district always vote together. Realistically voting schemes may be more complex, allowing for bicameralism, procedural provisions, checks and balances, vetoes.... Some of these aspects can be managed without abandoning the coalitional game approach of this paper. For example, appropriate coalition structures or compound games may be used. This might suggest interesting extensions of our work.

\section{Appendix}

Proof of Proposition 1. (i) Consider a game $(N, \gamma) \in \Gamma$. Without loss of generality, let $\gamma(N)=1$. Let us call $D_{i}(\gamma)=\left\{\Delta_{i}\right.$ $\gamma(S): S \subseteq N \backslash i\}$ the vector of $i$ 's marginal contributions to all the other players' coalitions, with $\Delta_{i} \gamma(S)$ defined as in (1). Given the convexity of game $\gamma$ (see Section 3 and footnote 4 ), $D_{i}(\gamma)$ is a vector in the $2^{n-1}$-dimensional unit-cube. Let $P$ be the $2^{n-1}$-dimensional vector of the coalition probabilities assigned by the Shapley solution in (1): $P=\{p(S): S \subseteq N \backslash i\}$, and $\mathbf{D}_{i}=\left\{D_{i}(\gamma):(N, \gamma) \in \Gamma\right\}$ be the set of all vectors of $i$ 's marginal contributions in games of $\Gamma$. It is easy to see that $\mathbf{D}_{i}$ is the unit-cube in $\mathfrak{R}^{n-1}$ and is a convex set, i.e. given any two points $D_{i}\left(\gamma_{0}\right), D_{i}\left(\gamma_{1}\right)$, with $\left(N, \gamma_{0}\right),\left(N, \gamma_{1}\right) \in \Gamma$, it is always possible to find a game $\left(N, \gamma_{2}\right) \in \Gamma$ such that $D_{i}\left(\gamma_{2}\right)=$ $(1-t) D_{i}\left(\gamma_{0}\right)+t D_{i}\left(\gamma_{1}\right) \in \mathbf{D}_{i}$ for any $t \in[0,1]$. By definition, $\varphi_{i}(\gamma)=D_{i}(\gamma) \cdot P$, which means that player $i$ 's Shapley value is a linear transformation of $D_{i}(\gamma)$. If $\Psi_{i}=\left\{\varphi_{i}(\gamma):(N, \gamma) \in \Gamma\right\}$ denotes the space of all player $i$ 's percentage Shapley values, then we can write $\Psi_{i}=\mathbf{D}_{i} \cdot P$, that is $\Psi_{i}$ is a linear continuous transformation of $\mathbf{D}_{i}$ in $\Re$. Since $\mathbf{D}_{i}$ is convex, then also $\Psi_{i}$ is convex. Namely, $\Psi_{i}=[0,1]$, which is a closed subset of the real numbers, and therefore is dense in $\mathfrak{R}$.

(ii) Now, let us call $\mathbf{D}_{i}(\Sigma)=\left\{D_{i}(v):(N, v) \in \Sigma\right\}$ the set of $i$ 's marginal contributions in all the simple games. The elements of any $D_{i}(v) \in \mathbf{D}_{i}(\Sigma)$ are only either 0 or 1 , therefore $\mathbf{D}_{i}(\Sigma)$ is a non-convex subset of $\Re^{n-1}$. Correspondingly, $\Psi_{i}(\Sigma)=$
$\left\{\phi_{i}(v):(N, v) \in \Sigma\right\}$ is the space of all player $i$ 's $S S$ values, with $\phi_{i}(v)$ defined by (2), therefore $\Psi_{i}(\Sigma)=\mathbf{D}_{i}(\Sigma) \cdot P$. Of course, $\Psi_{i}(\Sigma)$ is a continuous transformation of $D_{i}(\Sigma)$, but $D_{i}(\Sigma)$ is not convex, so $\Psi_{i}(\Sigma)$ is a non-dense subset of $\Psi_{i}=[0,1]$.

Proof of Proposition 2. Take $p(S)$ in the Definition 2 of political value. Recall that $p(S)=\frac{s !(n-s-1) !}{n !}$. Call $\Pi(n)$ the set of all possible values of $p(S)$. Notice that $\Pi(n)$ is coarse if $n$ is small, but, as $n$ increases, it becomes more and more populated. In the limit, $\Pi(n)$ coincides with the unit interval. Observe that in this case political solutions can be viewed as weighted sums of all elements in $\Pi(n)$ in which the weights can only be integers from zero to $2^{n}$ (see Definition 2 and footnote 7). If $n \rightarrow \infty$, then $\Pi(n) \rightarrow[0,1]$ and any point in $[0,1]$ can be a solution of a political game; i.e. it can be such a weighted sum of the points in $\Pi(n)=[0,1]$.

Proof of Proposition 3. Let $v$ be a political (weighted voting) game, and let $v^{\alpha}$ be the same voting game in which partners have the option of leaving the union if they pay a "fine" which is a share $(1-\alpha)$ of their option's payoffs (see Example 2). Let us re-write the political distortion in Definition 1 as:

$$
\begin{aligned}
P D_{i}(v, \gamma)= & \sum_{S \subseteq N \backslash i} p(S) \cdot\{[v(S \cup i)-\gamma(S \cup i)]+[\gamma(S)-v(S)]\} \\
P D_{i}\left(v^{\alpha}, \gamma\right)= & \sum_{S \subseteq N \backslash i} p(S) \cdot\left\{\left[v^{\alpha}(S \cup i)-\gamma(S \cup i)\right]\right. \\
& \left.+\left[\gamma(S)-v^{\alpha}(S)\right]\right\} .
\end{aligned}
$$

We may have three cases. Let us see how $P D_{i}\left(v^{\alpha}, \gamma\right)$ changes with respect to $P D_{i}(v, \gamma)$.

- First, observe that any player has an incentive to leave the union if $S$ is a minority. In this case, $v(S \cup i)=0$ and $v(S)=0$. Leaving the union and joining the minority $S$ yields $v^{\alpha}(S \cup i)=$ $\alpha \gamma(S \cup i)$ and $v(S)=\alpha \gamma(S)$. Both squared brackets in the LHS of $P D_{i}\left(v^{\alpha}, \gamma\right)$ can only decrease in absolute value and approach zero with $\alpha \rightarrow 1$.

- Second, if $i$ is the pivot in $S$, then $v(S \cup i)=1$ and $v(S)=0$. In game $v^{\alpha}$, the payoffs are: $v^{\alpha}(S \cup i)=\gamma(S \cup i)-(1-\alpha) \gamma(N \backslash$ $S \cup i)$ and $v^{\alpha}(S)=0$. The first squared brackets in the LHS of $P D_{i}\left(v^{\alpha}, \gamma\right)$ can only decrease in absolute value and approach zero with $\alpha \rightarrow 1$.

- Third, if $S$ is a majority, $v(S \cup i)=1$ and $v(S)=1$. In game $v^{\alpha}$, payoffs are: $v^{\alpha}(S \cup i)=\gamma(S \cup i)-(1-\alpha) \gamma(N \backslash S \cup i)$ and $v^{\alpha}(S)=\gamma(S \cup i)-(1-\alpha) \gamma(N \backslash S \cup i)$. Both squared brackets in the LHS of $P D_{i}\left(v^{\alpha}, \gamma\right)$ can only decrease in absolute value and approach zero with $\alpha \rightarrow 1$.

Thus,

$$
\begin{aligned}
& \frac{\partial P D_{i}\left(v^{\alpha}, \gamma\right)}{\partial \alpha}<0 \\
& \lim _{\alpha \rightarrow 1} P D_{i}\left(v^{\alpha}, \gamma\right)=0 .
\end{aligned}
$$

Proof of Proposition 4. By (2), no expected political distortion occurs if the $x_{m}(\gamma)$ 's solve the following system of linear equations $(m=1, \ldots, n)$ :

$$
\left\{\begin{array}{l}
1 \cdot x_{1}(\gamma)+\frac{1}{2} x_{2}(\gamma)+\cdots+\frac{1}{n} x_{n}(\gamma)=\varphi_{1}(\gamma) \\
\frac{1}{2} x_{2}(\gamma)+\cdots+\frac{1}{n} x_{n}(\gamma)=\varphi_{2}(\gamma) \\
\ddots \quad \cdots \quad \vdots \\
\frac{1}{n} x_{n}(\gamma)=\varphi_{n}(\gamma)
\end{array}\right.
$$


where equation $m$ is the expected SS of player $m$. For any $\gamma$, this system admits a unique solution,

$$
\left[\begin{array}{c}
x_{1}(\gamma) \\
x_{2}(\gamma) \\
\vdots \\
x_{n-1}(\gamma) \\
x_{n}(\gamma)
\end{array}\right]=\left[\begin{array}{c}
1 \cdot\left(\varphi_{1}(\gamma)-\varphi_{2}(\gamma)\right) \\
2 \cdot\left(\varphi_{2}(\gamma)-\varphi_{3}(\gamma)\right) \\
\vdots \\
(n-1) \cdot\left(\varphi_{n-1}(\gamma)-\varphi_{n}(\gamma)\right) \\
n \cdot \varphi_{n}(\gamma)
\end{array}\right]
$$

as for the generic $x_{m}(\gamma)$ this solution is Eq. (5).

Proof of Proposition 5. Let $p^{R}(\bar{\gamma})$ be the random selection voting rule for $(N, \bar{\gamma})$. Specifically, $p^{R}(\bar{\gamma})$ is a probability distribution over the set of $v^{m}$ such that $p^{R}\left(v^{m}(\bar{\gamma})\right)=\operatorname{Pr}\left(v^{m}(\bar{\gamma})\right)$ as defined in (5).

For any player $i$, the average political distortion is:

$\overline{P D}_{i}\left(p^{R}, \gamma_{j}\right)=\frac{1}{t} \sum_{j=1}^{t}\left[\phi_{i}\left(p^{R}(\bar{\gamma})\right)-\varphi_{i}\left(\gamma_{j}\right)\right]$.

Observe that for any $i$,

$\frac{1}{t} \sum_{j=1}^{t} \varphi_{i}\left(\gamma_{j}\right)=\varphi_{i}(\bar{\gamma})$

and

$P D_{i}\left(p^{R}, \bar{\gamma}\right)=0$

Therefore,

$\overline{P D}_{i}\left(p^{R}, \gamma_{j}\right)=\frac{1}{t} \sum_{j=1}^{t} \phi_{i}\left(p^{R}(\bar{\gamma})\right)-\varphi_{i}(\bar{\gamma})=0$.

Proof of Corollary 6. Observe that if $\Delta_{i} \bar{\gamma}(S) \equiv P_{i}$, for any $S \subset N$, and any $i$, then $\varphi_{i}(\bar{\gamma})=P_{i}$, for any $i$. Applying Propositions 4 and 5 completes the proof.

\section{References}

Alesina, A.F., Passarelli, F., 2010. Regulation versus taxation. Working Paper 16413 National Bureau of Economic Research.

Aleskerov, F., 2008. Power distribution in the electoral body with an application to the Russian parliament. ICER Working Papers - Applied Mathematics Series 11-2008 ICER - International Centre for Economic Research.

Amar, A.R., 1984. Choosing representatives by lottery voting. The Yale Law Journal 93, 1283-1308

Baldwin, R., Widgrén, M.T., 2004. Winners and losers under various dual majority rules for the EU council of ministers. CEPR Discussion Paper no. 4450, Centre for Economic Policy Research, London.

Barr, J., Passarelli, F., 2009. Who has the power in the EU? Mathematical Socia Sciences 57, 339-366.

Belke, A., Von Schnurbein, B., 2012. European monetary policy and the ECB rotation model. Public Choice 151, 289-323.

Benati, S., Vittucci Marzetti, G., 2011. Probabilistic spatial power indexes. Social Choice and Welfare, Online First, 14 October. http://dx.doi.org/10.0007/s00355011-0608-4.
Berg, S., Holler, M.J., 1986. Randomized decision rules in voting games: a model for strict proportional power. Quality and Quantity 20,419-429.

Braham, M., Holler, M.J., 2005. The impossibility of a preference-based power index. Journal of Theoretical Politics 17, 137-157.

Breton, M.L., Montero, M., Zaporozhets, V., 2012. Voting power in the EU council of ministers and fair decision making in distributive politics. Mathematical Social Sciences 63, 159-173.

Casella, A., 2005. Storable votes. Games and Economic Behavior 51, 391-419.

Casella, A., Ehrenberg, S., Gelman, A., Shen, J., 2010. Protecting minorities in large binary elections: a test of storable votes using field data. The B.E. Journal of Economic Analysis and Policy 10.

Felsenthal, D.S., Machover, M., 1998. The Measurement of Voting Power: Theory and Practice, Problems and Paradoxes. Edward Elgar, Cheltenham, England

Felsenthal, D.S., Machover, M., 2004. Analysis of QM rules in the draft constitution for Europe proposed by the European Convention, 2003. Social Choice and Welfare 23, 1-20.

Garrett, G., Tsebelis, G., 1999. Why resist the temptation to apply power indices to the European Union? Journal of Theoretical Politics 11, 291-308.

Gul, F., 1989. Bargaining foundations of Shapely value. Econometrica 57, 81-95.

Hart, S., Mas-Colell, A., 1996. Bargaining and value. Econometrica 64, 357-380.

Laruelle, A., Valenciano, F., 2003. Power indices and the veil of ignorance. International Journal of Game Theory 31, 331-339.

Laruelle, A., Valenciano, F., 2004. Inequality in voting power. Social Choice and Welfare 22, 413-431.

Laruelle, A., Valenciano, F., 2007. Bargaining in committees as an extension of Nash's bargaining theory. Journal of Economic Theory 132, 291-305.

Laruelle, A., Valenciano, F., 2008a. Noncooperative foundations of bargaining power in committees and the Shapley-Shubik index. Games and Economic Behavior 63, 341-353.

Laruelle, A., Valenciano, F., 2008b. Voting and collective decision-making. Cambridge Books, Cambridge University Press, Cambridge.

Laruelle, A., Valenciano, F., 2009. Cooperative bargaining foundations of the Shapley-Shubik index. Games and Economic Behavior 65, 242-255.

Laslier, J.-F., 2012. Why not proportional? Mathematical Social Sciences 63, 90-93.

Leech, D., 2002. Designing the voting system for the council of the European Union. Public Choice 113, 437-464.

Lpez-Guerra, C., 2011. The enfranchisement lottery. Politics, Philosophy \& Economics 10, 211-233.

Maskin, E., 2003. Bargaining, Coalitions and Externalities. Presidential Address to the Econometric Society, Institute for Advanced Study, Princeton.

Myerson, R.B., 1980. Conference structures and fair allocation rules. International Journal of Game Theory 9, 169-182.

Napel, S., Widgrén, M., 2006. The inter-institutional distribution of power in EU codecision. Social Choice and Welfare 27, 129-154.

Napel, S., Widgrén, M., 2011. Strategic versus non-strategic voting power in the EU council of ministers: the consultation procedure. Social Choice and Welfare 37. 511-541.

Passarelli, F., Barr, J., 2007. Preferences, the agenda setter, and the distribution of power in the EU. Social Choice and Welfare 28, 41-60.

Roth, A., 1988a. The expected utility of playing a game. In: Roth, A. (Ed.), The Shapley Value: Essays in Honor of Lloyd S. Shapley. Cambridge University Press, Cambridge.

Roth, A., 1988b. Introduction to the Shapley value. In: Roth, A. (Ed.), The Shapley Value: Essays in Honor of Lloyd S. Shapley. Cambridge University Press, Cambridge.

Sewell, R., Mackay, D., Mclean, I., 2009. Probabilistic electoral methods, representative probability, and maximum entropy. Voting Matters 26, 16-38.

Shapley, L.S., 1953. A value for $n$-person games. In: Kuhn, H., Tucker, A. (Eds.), Contribution to the Theory of Games, II. In: Annals of Mathematics Studies, 28. Princeton University Press, Princeton.

Shapley, L.S., Shubik, M., 1954. A method for evaluating the distribution of power in a committee system. The American Political Science Review 48, 787-792.

Turnovec, F., 2009. Fairness and squareness: fair decision making rules in the EU council? Operations Research and Decisions 4, 110-124.

Van den Brink, R., 2002. An axiomatization of the Shapley value using a fairness property. International Journal of Game Theory 30, 309-319. 